\title{
Exodus: How Migration is Changing Our World
}

Paul Collier, 2013, Nueva York, Oxford University Press, 309 pp.

\author{
María del Carmen VILLARREAL VILLAMAR \\ Universidad Complutense de Madrid
}

En este ensayo, Paul Collier, pera los tabúes y aborda los teprofesor de economía y políti- mas silenciados en relación con cas públicas de la Universidad la movilidad humana.

de Oxford, analiza la actuali- A partir de una amplia bidad del fenómeno migratorio bliografía y de recientes datos junto a sus desafíos presentes y estadísticos sobre el tema, Cofuturos. El trabajo está centra- llier trasciende el debate acerca do en la migración proveniente de si la migración es buena o de los países en desarrollo hacia mala para los países de origen los países desarrollados, pero y recepción y se centra en otros aborda también los flujos en elementos de creciente interés: dirección norte-norte, sur-sur y ¿Cuánta migración es buena norte-sur. Desde una perspecti- para las sociedades receptoras va multidisciplinar, enriquecida y de expulsión?, ¡cuáles son las por las aportaciones de campos mejores estrategias a disposición como la neuroeconomía, el au- para hacer de la migración un tor analiza la distancia entre rea- proyecto exitoso para todos? $\mathrm{Su}$ lidad e ideología en torno a las trabajo analiza a este respecto migraciones. Intenta para ello las consecuencias de carácter romper con los prejuicios y las económico, social y político en creencias más difundidas sobre las sociedades receptoras y colel fenómeno, al tiempo que su- ma uno de los vacíos existentes 
sobre el impacto de la migración en los países de expulsión al poner en evidencia, por ejemplo, los efectos del proceso en quienes permanecen en sus países de origen. Así mismo, tiene el mérito de realizar un análisis comparado de los modelos de integración, asimilación y multiculturalismo vigentes en las sociedades anfitrionas, al tiempo que aporta numerosos ejemplos, estudios recientes y modelos económicos que permiten una fácil comprensión de estos complejos temas.

Su ensayo es una obra provocativa que invita a la reflexión profunda acerca de uno de los fenómenos más importantes de la actualidad. Al margen de la instrumentalización creciente que se realiza del fenómeno migratorio, especialmente por sectores políticos populistas, la migración es vista por el autor como una respuesta a la prosperidad que no se ha globalizado y a las asimetrías globales en términos de bienestar económico, político y social. Su tesis central es que los flujos migratorios limitados y organizados pueden ser benéficos para todos, mientras que una inmigración no regulada puede traducirse en un éxodo sin precedentes con graves repercusiones para las sociedades receptoras y de expulsión, así como para los mismos migrantes.

A partir de presupuestos éticos y del análisis empírico de los efectos en los contextos de expulsión y recepción, el autor ilustra las motivaciones que justifican la necesidad de regular los flujos migratorios. Desde una perspectiva holística, su trabajo tiene además el mérito de abordar los múltiples vínculos que hay entre migración y desarrollo.

Para una mejor comprensión de las migraciones y sus desafíos a nivel global, el libro está dividido en cinco partes. En la primera sección el autor se interroga sobre los factores que dan origen al fenómeno migratorio global y los elementos que han impedido hasta la fecha un tratamiento realista del tema. En su opinión, existe un tabú en torno al fenómeno migratorio que ha generado, por un lado, la incompetencia política para comprenderlo y, por otro, la formulación de políticas erróneas para manejarlo. Más que debates serios sobre el fenómeno migratorio, parecen prevalecer un 
conjunto de buenas intenciones que, sin embargo, se han revelado incapaces de ofrecer soluciones. La gente de los países del sur del mundo se mueve en razón de las enormes desigualdades que persisten entre sus países y los países desarrollados, buscando así una mejor vida de la que aspiraría en su lugar de origen. Además, factores como la atracción que ejerce el estilo de vida occidental, las facilidades brindadas por el desarrollo de nuevas tecnologías y transportes, la importancia que revisten las diásporas residentes en las sociedades anfitrionas para estimular la movilidad, no hacen sino aumentar las probabilidades de que la inmigración en los próximos ańos crezca y pueda convertirse en un éxodo futuro.

En la segunda parte el autor se interroga sobre el contexto de recepción, y analiza las consecuencias sociales, económicas y políticas de la inmigración. Si en un primer momento la inmigración es benéfica para las sociedades receptoras, el objetivo central reside en conocer cuándo ésta deja de ser un valor agregado y puede traducirse, por el contrario, en un factor que mine la cohesión social de las mismas, además de dar lugar a procesos de emigración de la población local. Con base en las experiencias de Inglaterra, Canadá, Estados Unidos y Australia, el autor considera los beneficios sociales y las desventajas que brindan los modelos multiculturalistas e integracionistas. A este tenor, desde una perspectiva comparada se abordan numerosas cuestiones que atañen a la inmigración en las sociedades receptoras, tales como los efectos de la concentración o las escuelas diferenciadas que agrupan inmigrantes por un lado y población nativa por otro. De forma paralela, no faltan referencias constantes a los desafíos que estos factores suponen para el reconocimiento de una ciudadanía de pleno derecho de los inmigrantes, así como respecto a la identidad nacional, el laicismo o la igualdad de género parcialmente vigente en los países anfitriones.

En la tercera parte, el autor considera el proyecto migratorio como una inversión y analiza, por lo tanto, sus efectos en términos de éxito y fracaso. Estudia en este sentido los costos y las desventajas de la inmigración, y llega a la conclusión de que en determinadas ocasio- 
nes ésta puede ser un proyecto erróneo para sus protagonistas. Basándose en investigaciones recientes, el autor señala que en igualdad de condiciones los inmigrantes declaran ser menos felices y tener menos bienestar que sus compatriotas residentes en sus países de origen. Ante este hecho, argumenta que si en un primer momento los inmigrantes pueden obtener beneficios cambiando su lugar de residencia, cabe preguntarse cuándo dichos beneficios se reducen, llegando incluso a desaparecer y si los mismos podrían mantenerse con flujos inmigratorios crecientes en las sociedades receptoras.

En la cuarta parte se analizan las consecuencias económicas y políticas de la migración para quienes no cambian su lugar de residencia. Así, se evidencia que si por un lado las remesas, las diásporas y la migración de retorno ofrecen potenciales beneficios para el desarrollo, la democracia o el respeto de los derechos humanos en los países de origen, pueden traducirse también en fuentes de inestabilidad política y económica para los mismos. Al margen de la heterogeneidad de los efectos que la migración puede generar en quienes se quedan atrás, el argumento central de este apartado es comprender cuánta migración es benéfica para quienes residen en los países expulsores y cuándo ésta deja de ser un factor conveniente tanto para los que residen en tierras foráneas como para los que deciden permanecer en sus países de origen.

Por último, en la quinta parte se examina la necesidad de reconsiderar las políticas migratorias adaptándolas a la realidad del fenómeno migratorio y las posibilidades de absorción de las sociedades receptoras. Más allá de presupuestos individualistas o universalistas, el autor se interroga sobre la importancia de factores como el aprecio mutuo, la cooperación, el respeto y la generosidad para el funcionamiento de una sociedad. Ahonda para ello en los retos que supone para las sociedades receptoras la llegada constante de flujos de inmigración destinados a aumentar en los ańos venideros, y la necesidad de encontrar soluciones adecuadas que garanticen su correcta integración y plena ciudadanía. Además, Collier esboza numerosas propuestas para permitir que el fenómeno migratorio fa- 
vorezca a los países involucrados y a sus protagonistas, sin que se evadan las responsabilidades de los Estados en la garantía del bienestar de sus poblaciones.

En síntesis, este libro constituye un aporte esencial al estudio y comprensión del fenómeno migratorio $y$ es una obra de obligada lectura para los interesados en el tema desde múltiples perspectivas. Plantea serios desafíos a un abordaje del fenómeno migratorio humanista y respetuoso de los derechos y libertades individuales. Posee así mismo un tono alarmista y aborda de manera marginal cuestiones como el papel de los países desarrollados en la migración global, la importancia de las corrientes migratorias en épocas pasadas y la experiencia de regiones como América Latina en la absorción de las mismas. Adolece también de soslayar las transferencias netas que se realizan desde los países emisores o la importancia de la clase social en la selección e integración de los migrantes. No obstante, tiene el mérito de tratar controvertidos argumentos desde presupuestos realistas y poner sobre la mesa temas necesarios que requieren soluciones basadas en algo más que la buena voluntad o el idealismo. 